VARIA 



\title{
TIPOLOGÍAS DE LA PROSCRIPCIÓN VISUAL
}

\section{Carolina Sanabria}

\begin{abstract}
RESUMEN
El siguiente artículo pretende sistematizar las principales formas o tipologías de proscripción visual que a lo largo de la historia han sido en mayor o menor medida han sido defenestrados del imaginario visual. Así pues, este trabajo formaliza cuatro tipos básicos vinculados con lo que atañe esencialmente a la mostración del cuerpo. En tanto tales, provienen de actitudes subjetivas (el narcisismo y el voyeurismo), así como de las representaciones que tienen que ver con el sexo explícito (la convención pornográfica) y la imagen convencionalizada de la muerte.

Palabras clave: mirada, representación, narcisismo, voyeurismo, pornografía, muerte
\end{abstract}

\begin{abstract}
The following article attempts to systematize the main forms or typologies of visual proscription which, throughout history, have been banned from visual imagery to a greater or lesser extent. Thus, this work formalizes four basic types linked to what essentially concerns the display of the human body. Being so, they originate from subjective attitudes (narcissism and voyeurism), as well as from the representations that have to do with explicit sex (the pornographic convention) and the conventional image of death.
\end{abstract}

Key words: gaze, representation, narcissism, voyeurism, pornography, death

\section{Preámbulo}

Una de las constataciones más relevantes de la cultura visual durante el siglo pasado es que la tradición que durante tanto tiempo ha ligado la mirada con el intelecto -elevado, aferrado a la verdad científica- se erige sobre pedestales inconsistentes. La recuperación en el arte de la sensibilidad de la abyección (Clair 2007) demuestra que la mirada puede de igual

\footnotetext{
Carolina Sanabria. Doctora en Comunicación Audiovisual y Publicidad de la Universidad Autónoma de Barcelona. Catedrática de la Escuela de Estudios Generales de la Universidad de Costa Rica. San Pedro, San José, Costa Rica. Correo electrónico: csanabriacr@yahoo.com
} 
manera someterse a una desviación perversa, circunscrita, como no podía ser de otra forma, a la sempiterna obsesión, el cuerpo: suceso corrompido, maldito del conocimiento que perturba el orden y desvía el sentido original y purificado de la contemplación, en cuanto a lo que el idealismo platónico y cristiano ha exaltado como el Bien. De ahí procede el bíblico tabú de la mirada, que inaugura su interpretación de la creación humana a partir del incidente mitológico de la desobediencia del mandato divino por Adán y Eva, con el corolario de la reparación en su desnudez (lo que da paso inmediato al cubrimiento, esto es, a la expresión de la vergüenza y de la culpa) (Génesis 3: 7-8).

No existe una purificación original o inherente. La fuente sustancial de la vergüenza (lo abyecto) se hace ubicar en lo que se relaciona con un contacto directo con lo exterior, ya sea mediante su introducción -el alimento, el sexo (lo ligado con la satisfacción de las necesidades primarias, desvaloradas por la tradición eclesiástica)- como su expulsión -emanaciones, excreciones y demás efusiones $^{1}$ (en especial del cuerpo femenino)-: todo lo que violente los límites entre el afuera y el adentro -que empieza por irrespetar el propio ser humano, cuyo trayecto inaugural hacia la vida transita por esa misma ruta ${ }^{2}-$.

\footnotetext{
Lo que provoca la experiencia de la abyección", sostiene Nead a partir de uno de los últimos textos de Kristeva, "es el reconocimiento del individuo de la imposibilidad de una identidad estable y permanentemente fijada. Los objetos que provocan abjección [sic] son aquellos que atraviesan el umbral entre el interior y el exterior del cuerpo: lágrimas, orina, heces y así sucesivamente. Lo abyecto, pues, es el espacio entre sujeto y objeto; el lugar tanto del deseo como del peligro" (1998: 57).
}

No tan perceptible como el aparato fisiológico, la mirada funciona según ese mismo itinerario: desde la pulsión (interior) hay una atracción hacia las imágenes (exteriores). Esto quiere decir que la mirada no solo se forja por significaciones de la conciencia: tiñe de interioridades -incluidas las abyecciones que se configuran en el inconsciente- lo que contempla -por eso es personal pero también intransferible-. De este modo se constituye un abanico que permite identificar variables exiliadas -injuriadas- de la percepción, en las que se propone una reivindicación del deseo producido a través de la experiencia de la mirada ${ }^{3}$.

\section{La mirada narcisista}

En la mitología grecolatina, una de las miradas prohibidas más emblemáticas es la de Narciso. El mito -al que Melchior-Bonnet considera como una creencia arcaica en la existencia de un doble o del alma (1996: 120)- coexiste con otras versiones que presentan ligeras variaciones, aunque sustancialmente mantienen la misma base, esto es, el ser amado que constituye el fin y la satisfacción en la elección narcisista del objeto (Freud 1973: 33) -y desde un enfoque cristiano, la falta de Narciso respondería a que, en la refocilación por su forma corporal, descuida la auténtica belleza para abalanzarse sobre un reflejo que de ninguna manera puede llegar a colmar nunca las aspiraciones de su espíritu (Melchior-Bonnet 1996: 131)-.

Precisamente en otra de las variantes del mito de Narciso -la de Filostrato-, Dubois destaca un deslizamiento a nivel discursivo, que tiene lugar cuando el sujeto de la enunciación deja a un lado la narración en tercera persona y pasa a adoctrinar directamente al personaje a través del tuteo -con lo que enunciado y enunciación se implican a nivel especular- (1986: 130), muy semejante a la interpelación que figura en el relato de Ovidio: "Crédulo, ¿para qué intentas en vano coger fugitivas imágenes? Lo que tú buscas no está en ninguna parte; lo que tú amas, apártate y lo perderás. Esa sombra que estás viendo es el reflejo de tu imagen” (III, 
430). Se está, pues, ante una apelación circular -o mejor, reflectante- en el mismo discurso que recrea el conflicto que vive el propio personaje -más clara aun en el texto de Filostrato, cuyo narrador, dirigiéndose al personaje, le eleva la pregunta casi moebiana: “¿Crees que la fuente entablará conversación contigo?" (en Dubois 1986: 131)-.

El tema del joven que se deleita extasiado con su reflejo en un estanque fue explotado como parte de un repertorio amplio de imágenes visuales en donde el orgullo y la vanidad, como argumenta Jonathan Miller, se identifican con una preocupación por la apariencia física: "The suggestion seems to be that the individual who is entranced by her own appearance could be just as dangerously in love with the secret configurations of her inner self" (1998: 161). Especialmente entre finales de la Edad Media y el Renacimiento, el narcisismo deriva en vanidad y soberbia -delegadas esta vez en una mujer que mira su reflejo-. Tales imágenes operan desde una doble actitud. Conforman una recreación del propio placer visual al tiempo que contienen una condena moral por la presencia de elementos que rodean al personaje bajo el categórico signo del espejo ${ }^{4}$. Este es el caso de Vanidad (1485) de Hans Memling o de grabados como Coquetería diabólica de Albretch Dürer, con base en la representación moralizadora del diablo agazapado detrás de la mujer que se contempla (Melchior-Bonnet 1996: 219): un topos que se mantendría en épocas sucesivas, pues "[c]on las censuras del cristianismo, la imagen femenina que se acicala se convirtió en una advertencia contra los peligros del pecado accesorio de la vanidad" (Manguel 2003: 207)-.

El uso del término se remonta a 1899, cuando Näcke lo utilizó por primera vez para designar los casos clínicos en los que un individuo toma su propio cuerpo como objeto para fines sexuales y de apercibimiento. De esta definición inicial se desgaja el vínculo básico que admite plantear una relación entre narcisismo y voyeurismo, esto es, que la mirada se ejerce inicialmente sobre el propio cuerpo y luego es transferido o extrapolado a otro, como plantea el propio Freud: "El instinto de contemplación es [...] autoerótico al principio de su propia actividad; posee un objeto, pero lo encuentra en el propio cuerpo. Sólo más tarde es llevado (por el camino de la comparación) a cambiar ese objeto por uno análogo del cuerpo ajeno" (2004: 154).

La interpretación psicoanalítica parte del mito para referirse a la formación imaginaria del yo. Encaminado hacia la construcción identitaria, toma como base a Narciso en tanto prototipo de aquel ser humano cautivado por la belleza de una imagen que no sabe reconocer como propia, de modo que el principio sobre el que se sustenta la teoría es el desconocimiento de la propia identidad. Previo a la elección de un objeto con el cual identificarse, hay un estadio primitivo en el que la confusión no permite distinción alguna con el otro. Inseparable de esta experiencia es la fase del espejo, ligada a la identificación -en la que se suele localizar formalmente la aparición del narcisismo primario-, donde tiene lugar la captación amorosa del sujeto por el deseo. A partir de una relación especular, el valor cautivante del otro reside en que lleva al sujeto a construir su identidad:

El sujeto localiza y reconoce originariamente el deseo por intermedio no sólo de su propia imagen, sino del cuerpo de su semejante. Exactamente en ese momento, se aísla en el ser humano la conciencia en tanto que conciencia de sí. Porque reconoce su deseo en el cuerpo del otro el intercambio se efectúa (Lacan 1981: 223).

He aquí, pues, la maniobra que convierte al narcisismo en voyeurismo y viceversa: el placer de autovisualización -que puede mutar en exhibicionismo- es una ramificación del deseo escópico. El fenómeno resulta particularmente claro en la situación de visionado fílmico que 
recrea Rear Window (1954), el célebre film de Alfred Hitchcock donde el espectador se identifica (unifica) con el protagonista, L. B. Jefferies, que a su vez transfiere su imagen (por trasposición de su deseo) a lo que ve, es decir, a ese personaje que está convencido de que otro (reflejo de la ventana) es un asesino ${ }^{5}$. La pantalla, entonces, se transforma en un espejo no solo para Narciso, sino para el espectador (voyeur), con sus mismas propiedades pero también con sus riesgos.

\subsection{Superficies que absorben}

Mediación visual que posibilita la devoción solitaria, el espejo se configura como una superficie reflectante que in(sti)tuye el ritual de la (auto)seducción donde el sujeto mismo se convierte en el centro exclusivo de atracción ${ }^{6}$. Punto donde concentra su atención, el cuerpo desplaza a Dios, lo que contribuye a explicar el carácter prohibido (corrompido) de una actividad que practica aquel que prefiere dedicar sus mimos a la apariencia personal, que antepone una devoción personal, material (pasajera), antes que una preocupación espiritual, intangible nueva vuelta al dualismo platónico-. Pero la auténtica imagen de Dios tampoco existe -es una entidad abstracta, informe y, como tal, irrepresentable-, con lo que la iconografía creada a su alrededor soporta el que se le termine venerando como a un becerro ${ }^{7}$ (por lo demás, acto no infrecuente en las arrebatadas sectas de esta era finisecular). En cambio, tradicionalmente ensañada contra el cuerpo, la institución eclesiástica promociona, en especial a raíz del ejercicio de algunas prácticas como las inquisitoriales, el mecanismo por contraste de la glorificación del alma. Tributaria del Fedón, propone la separación estoica de un cuerpo en cuyas pasiones reina la impureza. La imagen medieval, bastante distinta de las actuales, carecía de una manifestación sensible, y si la tenía, era considerada pura apariencia terrestre, desprovista de valor frente a las entidades inmateriales (Aumont 2002: 333). No obstante, el Renacimiento da lugar a una valoración de la imagen mundana, a un secular -aunque evidentemente gradualrelevo de atención que, a diferencia de la divina, se volatiliza con el tiempo.

Por si fuera poco, el contacto del hombre con el espejo era recomendado por Alberti y Leonardo en los usos de la pintura -sobre todo de autorretratos-. En tanto resuelve el encuentro con ese ser amado que no es otro más que sí mismo -a costa, claro está, de su muerte-, la mirada narcisista contendría cierta dosis de condena. En los tres tipos de miradas -pornográfica, voyeurista y narcisista- late la intimidación ante la amenaza de ser descubierto en el ejercicio de contemplación. Al contar con una sanción social bastante más débil, no sería, en principio, disparatado pensar la narcisista como la menos conminatoria, la de menor consideración -aun cuando todas puedan, a lo sumo, derivar en contención o turbación en el sujeto que se mira-. Nada, sin embargo, más infundado, pues como Melchior-Bonnet sostiene, esta mirada es la que reviste mayor gravedad, la que puede suscitar mayores reprobaciones y recelos: "La mirada volcada hacia uno mismo, hacia el cuerpo, es la más culpable de todas las miradas, el fermento de todas las vanidades" (1996: 229), incluso aun entrado el siglo XVII, cuando el instrumento de autocontemplación ya formaba parte de los objetos de uso cotidiano. La desconfianza de su naturaleza se acentúa si se tiene en cuenta su carácter fractal, dominado por las configuraciones que se generan, de reproducción (infinita) de objetos (finitos): de ahí la sentencia de uno de los heresiarcas de la fantástica tierra de Uqbar-Copulation and mirrors are abominable-, la cual atribuye un carácter excecrable a los espejos (y a la cópula) porque son artificios que multiplican el número de los hombres (Borges 1985: 14- 15)-. Semejante a como opera el valor exhibitivo de la obra de arte, se está entonces una vez más ante el carácter 
de repetición inagotable que inspira los simulacros, lo que en última instancia supone el engaño de la fidelidad, puesto que la imagen deja de ser siempre la misma: pierde su carácter cultual (Benjamin) -algo de lo que ni la estacionaria iconografía de Dios puede abstraerse-. Sin embargo, no se trata sólo de un acto de adoración destinado hacia sí mismo, pues la superficie que permite la mirada es la misma y a la vez la que se interpone con la posesión del objeto amado -es imposible que Narciso llegue a poseer a ese a quien ve, de donde procede su muerte como inevitable: "Amar, morir, es ser presa de una mirada, y a veces de la misma mirada" (Starobinski 2002: 27)-. Formulado como embelesamiento ante la apariencia -como disimulo, como falsedad-, el espejo (se) desvía del camino de la verdad, pertenece al mundo de las ilusiones, de lo efímero (constatado por su estrecha relación con el espejismo): no es casual que Dante lo confine al infierno de los falsificadores. Ciertamente dentro de sus particularidades reside el conjugar la seducción de la propia imagen con la muerte: es el propio reflejo -superficial, en absoluto profundo- el que absorbe, el que seduce a Narciso, a ese otro que no es más que él mismo.

Dubois, que analiza la mencionada versión de Filostrato entre otras razones por ser “el único que evoca la historia de Narciso por intermedio de la pintura" (1986: 128) ${ }^{8}$, plantea asimismo que en ella existen dos instancias de representación: una intradiegética -Narciso mirándose en la fuente, totalmente imbuido en su propia imagen en un acto que excluye al espectador, circunscrito como voyeur de una relación amorosa- y otra extradiegética -el espectador mirando(se) en el cuadro, ya no escindido, separado, sino implicado, identificado-, la cual no hace sino revelar que toda mirada sobre un cuadro es narcisista (como búsqueda del reconocimiento, de lo familiar, en última instancia, de sí mismo).

\footnotetext{
"Si la imagen”, dice Dubois, "que observa Narciso en su propio reflejo 'pintado' y si el cuadro, como la fuente, es también una pintura 'reflejo', entonces lo que refleja será siempre la imagen del espectador que lo observa, que allí se observa. Soy siempre yo pues el que me veo en el cuadro que miro" (1986: 129).
}

Toda representación consta, por tanto, de un componente narcisista en la medida en que el despliegue de su poder de seducción demanda un reconocimiento de sí: "En la alquimia del acto creador, todo retrato es un espejo" (Manguel 2003: 191). Claro que no serán solo el cuadro y el espejo los únicos campos de visibilidad que hechizan: otras superficies (pantallas), como las cinematográficas ${ }^{9}$, televisivas e informáticas, ejercen similares efectos de conjura, algunos en ocasiones parangonados con los hipnóticos.

Históricamente, esta atracción narcisista está latente en la ancestral búsqueda de lo mismo que la Edad Media recupera al procurar una conexión más íntima entre Dios y su creación a imagen y semejanza, de acuerdo con el Génesis ${ }^{10}$. Los primeros rastros de la busca se remontan al conocido mito platónico, más pagano que el cristiano pero no por ello menos idealista, según el relato de Aristófanes en El banquete ${ }^{11}$. De este mito procede no sólo el arquetipo del otro como completud ("lo semejante atrae a lo semejante"), sino su posterior elaboración lacaniana donde reconoce que, desde el momento de su nacimiento, se instaura en el sujeto una fractura, una bipartición (ezquizia) (1999: 113) -destinada a no colmarse nunca-.

Sea pues en calidad de espejo o de video, lo que distingue a las superficies reflectantes es la frágil naturaleza de la representación: ésta no pierde su carácter inestable, perecedero, no deja nunca de estar sujeta a los rayanos límites de caducidad que rubrican hasta el más trivial de los artículos de consumo -ya constatado por la tecnología del video: la posibilidad que sus cintas y discos contienen de borrar imágenes previamente grabadas hace que estas se vuelvan 
más evanescentes que nunca-. Sin duda, el ámbito de lo efímero es el terreno irrevocable donde se inscribe la comunicación de masas ${ }^{12}$.

\subsection{El otro en el reflejo}

La naturaleza del reflejo coincide con la de una superficie inquietante que ofrece una proximidad exacta e imperfecta. La idea, de Melchior-Bonnet, se fundamenta en el hecho de que el espejo no respeta fielmente a su modelo -en él la inversión es elemental: la derecha es la izquierda y viceversa-, se disgrega la ubicación de la imagen -que está aquí y allá al mismo tiempo- y crea una posición y una profundidad perturbadoras - de manera que no es extraño que quien se contempla en él confunda su propia superficie y lo que ve a través de ella- (1996: 119): "más fiel que la de una copia pintada, esta imagen no posee ni substrato ni consistencia", es decir, escapa a todos los sentidos excepto a la vista (Melchior-Bonnet 1996: 122).

En el campo pictórico, Diego Velázquez logró captar esta dinámica en su celebérrimo óleo La familia de Felipe IV (1656) -mejor conocido como Las Meninas-desde una compleja articulación especular en la que la estructura tradicional del espectador que mira la figura del cuadro se revierte al pintor que mira al espectador mirando.

\footnotetext{
En el momento en que colocan al espectador en el campo de su visión, los ojos del pintor lo apresan, lo obligan a entrar en el cuadro, le asignan un lugar a la vez privilegiado y obligatorio [el de los reyes], le toman su especie luminosa y visible y la proyectan sobre la superficie inaccesible de la tela vuelta (Foucault 2001: 15).
}

A través del juego de espejos y reflejos que cuestiona el propio acto de visión -condensado por Rafael Argullol bajo la expresión "¿Quién mira a quién y desde dónde se mira?" (en Portús 1994: 63)-, el despliegue de la mirada recompone en el mismo lienzo la personificación de las miradas intersectas: la del pintor, la de la infanta, la de los reyes (o mejor, la de su reflejo), confundidos con la del espectador (y viceversa).

Pero si bien el reflejo especular no corresponde a ninguna realidad autónoma, basta que se forje en una corporización fidedigna para mantener la identificación. "La idea subyacente es siempre la misma: en tanto que una imagen sea semejante al original, es igual, idéntica a él", dice Ladner (en Freedberg 1992: 438). Se establece entonces una relación comparativa entre la identidad y el parecido, que funda la ecuación entre semejanza e identidad -el referente se confunde con su imagen, la forma termina encarnada en la idea: esta posibilidad de fusión es lo que, para Freedberg, garantiza la efectividad de las imágenes (1992: 448) - y que constituye también el principal motivo por el que se fetichiza la iconografía -estatuas, fotografías- de líderes políticos o de seres amados sobre los que se vuelcan las hostilidades y los afectos (no necesariamente en disposición respectiva) -aunque, tratándose de símbolos religiosos, las reticencias provienen del hecho de que, para algunos teólogos, inculca la idolatría-.

Pese a que su vinculación no es directa con la mirada narcisista, el originario reflejo sobre las aguas contribuye a explicar fenómenos antropológicos y psicológicos, en concreto de formación de la personalidad. Por eso Argullol llega a plantear que el reflejo de uno mismo consiste en un tipo de conocimiento casi equivalente al principio socrático del conócete a ti mismo (en Portús 1994), que los cristianos recuperan luego en tanto forma de interpretación del conocimiento de uno mismo como una forma de orientarse a la divinidad. Consideraciones teológicas aparte, el reconocimiento de sí mismo frente a los otros, empero operar en un nivel puramente -inicialmente- superficial, es el primer paso para la formación de la conciencia de la identidad. En este sentido, el reflejo deja al 
descubierto la alteridad del sujeto, o como diría Gubern, "la otredad como mismidad" (1988: 18), donde todo proceso identitario siempre se construye - esto es, autoriza el autoconocimiento- desde la interacción con lo ajeno, lo diferente.

El descubrimiento de un referente en el reflejo marca entonces la conformación de esta conciencia de identidad, íntimamente ligada a la apropiación de los primeros rudimentos del lenguaje: "La posesión del pronombre yo permitió la reflexión del sujeto sobre sí mismo [...] hasta el punto que no es exagerado afirmar que con la verbalización interiorizada de la imagen del Yo surgió el psiquismo humano" (Gubern 1988: 18). Esta relación especular se extrapola a la lengua, como lo evidencia la teoría del lenguaje en la constitución de la identidad según Benveniste, para quien todo enunciado adquiere la forma (auditiva) de un reflejo - un eco ${ }^{13}$ del sujeto que lo emite: "El lenguaje sólo es posible porque cada locutor se pone como sujeto remitiendo a sí mismo como yo en su discurso. Así, yo afirma a otra persona, aquella que, por exterior que sea el 'yo' (moi), se convierte en un eco al que yo digo tú y que me dice tú" (en Dubois 1986: 132). No sólo eso: en realidad, cualquier intercambio dialógico supone una reafirmación integral del componente narcisista si se concede que toda situación comunicativa surge bajo la pretensión de con/vencimiento - de manipulación- del otro, de asumirlo -de absorberlo- bajo mi discurso -lo que explica la valoración de la retórica (que los sofistas popularizan como método) en la Grecia Clásica-.

A partir de las derivaciones especulares, el narcisismo trae aparejado el tema del otro; entonces "el hombre y su reflejo dejan de ser solidarios: su divergencia toma cuerpo ante el espejo, hasta tal punto que la imagen especular se emancipa y, en último extremo, ya no es percibida como un fenómeno óptico, sino como un rival amenazador" (Melchior-Bonnet 1996: 268). La ficción ha recurrido a este planteamiento con bastante frecuencia, elaborando un otro o doble idéntico ${ }^{14}$ al protagonista que escamotea dimensiones perversas (el doppelgänger teorizado por los románticos alemanes). No resulta por tanto extraño que esta figura pueda tomar la forma de un monstruo - de lo cual ya dan fe los bestiarios de la antigüedad grecolatina más tarde reelaborados por los medievales-: de hecho, su misma etimología, monstrum, procedente del latín, remite a la visibilidad, al acto y al valor exponencial -es lo que, aun cuando permanezca oculto, está para ser mostrado (monstrare), regido básicamente por un efecto desculpabilizador-. Poe, Maupassant, Shelley, Stevenson...: el otro ha sido una constante en la historia del pensamiento y en la construcción de las sociedades -acaso uno de los signos definitorios de la contemporánea- ${ }^{15}$.

En buena parte de estos casos, tal tipo de seres se origina en un efecto siniestro (unheimlich ${ }^{16}$ ) que, según Freud en su hermoso ensayo de $1919^{17}$, tiene que ver más bien con lo que procede de lo familiar, lo íntimo, lo hogareño (heimlich) sobrevenido extraño por el proceso de represión: "El hombre es, pues, unheimlich", interpreta Braunstein, "porque se sale de los límites de lo familiar, del lugar en el que ha surgido, a través de una actividad violenta" (1981: 198): situación que puede tener las más inimaginables representaciones - como las de Wright ${ }^{18}$ dentro del llamado orden represivo de la cultura, esto es, la realización de la fantasía de retornar al claustro materno. Esta manifestación se instalaría, de nuevo, en el ámbito de la atracción por lo semejante, tal y como sucede en la obra cumbre de García Márquez, en la que la temible marca de los miembros de la estirpe Buendía brota, venciendo, implacable, la contenida resistencia de varias generaciones, fruto de unas relaciones tan endogámicas (narcisistas) como ominosas (destructivas): no en vano lo más siniestro, parafraseando los versos corales de la tragedia de Sófocles Antígona (hacia el 442 a.C.), no reside sino en lo que proviene del hombre mismo. 


\section{La mirada voyeurista}

En términos ampliamente generales, la mirada voyeurista conjuga el acto visual con motivaciones sexuales del orden de lo inconsciente -ya lo constata Freud: "La impresión visual es el camino por el que más frecuentemente es despertada la excitación libidinosa" (1975: 25)-. Sin embargo, aunque el voyeurismo es una estructura en la que toma parte la composición biológica, también participan configuraciones sociales de las estructuras del erotismo de carácter sociocultural ${ }^{19}$.

Modalidad constitutiva de la visión que se asienta en lo inconsciente, esta forma de mirada se caracteriza por ejercerse de manera furtiva sobre las intimidades ajenas ${ }^{20}$. Pero entraña asimismo una limitación que frena a su espectador a tomar parte del acto -porque el goce es ante todo visual-. Por esta razón, el voyeur normalmente es una presencia inocua ${ }^{21}$ -como lo enunciaba el elocuente y alarmista titular, a inicios de la década de los noventa, de uno de los principales (y más conservadores) diarios de España: "Sólo el 1 por 100 de los exhibicionistas y mirones recibe tratamiento psicológico" (ABC 05/08/91: 48 $)^{22}$-. Ante todo, el voyeurismo destaca como un síntoma subrepticio -jamás reconocido pero sí practicado-, potenciado por la apertura de las nuevas ventanas -las electrónicas-, con lo que el fenómeno cobra una rediviva expresión (y expansión).

\section{La mirada sexual (la representación pornográfica)}

Una puntualidad imposible de mayor postergación habría de matizar que tanto el narcisismo como el voyeurismo proceden de una actitud subjetiva, mientras que lo que se ha establecido como una convención -la pornografía- deriva de una mirada centrada exclusivamente en la sexualidad, y como tal ha venido a estructurarse en una representación, que es cosa distinta (Gubern 22/04/05). Sin embargo, las tres parten de un mismo punto de articulación: la tendencia escoptofílica, o mejor, el deseo que deviene búsquedas solitarias de la fascinación ante las representaciones del cuerpo.

$\mathrm{Si}$, desde un enfoque freudiano, la mirada narcisista (la visión sobre el propio cuerpo) se planteaba como una suerte de circunstancia previa a la actividad del voyeur (la contemplación subrepticia del otro) -donde se procede a una suerte de desplazamiento u operación extensiva que supera los límites iniciales de visualidad-, en este tipo de mirada, la visión se altera: pierde su carácter furtivo y se expande sobre un nuevo foco de atención: la exacerbación explícita de lo sexual -entendiendo por tal el área (y la actividad) sobre los que se establece un alto interés escópico "como estímulo óptico de alta pregnancia emocional" (Gubern 2004: $225)^{23}$-. "Lo que se desahoga", dice Sontag con respecto a las representaciones de este tipo, "es una reacción sexual, que ha sido inicialmente voyeurística pero que probablemente necesita reforzarse mediante una identificación directa subyacente con uno de los participantes en el acto sexual" [énfasis agregado] (1985: 64). Por tanto, ambas miradas, la narcisista y la sexual, vienen a constituirse en los vértices que articulan una visualidad marginal (con una carga, en algunos momentos de la historia, altamente ilícita) en la que el voyeurismo se perfilaría como una estación de paso o estadio intermedio.

En los orígenes del cine llamado primitivo, florecieron los llamados film-voyeur, un tipo de películas, según Gubern, en los que "aparecía una silueta de cerradura en la pantalla y tras ella una mujer se quitaba algunas prendas”, aunque quedaba muy protegida por una extensa 
ropa interior, "porque esta temprana propuesta de cámara subjetiva no permitía ver lo que se vería en realidad por un ojo de cerradura, sino lo que la severa censura de la época permitía que se viera, a modo de aperitivo para el mirón" (2004: 239-240). No es casualidad que en algunas de las cintas fundacionales de la pornografía o hard-core -donde el énfasis invariablemente recae en lo sexual- como Am Abend (1910), El Satario (1907-1912) y A Free Ride (1917-1919), el común denominador, en las secuencias de introducción, consista en la coyuntura narrativa de observación de algunos personajes, oculta la mayor parte de las veces sobre la intimidad de los otros (Williams 1990: 68). Tampoco es casual que uno de los primeros filmes eróticos -de nacionalidad francesa y de fecha incierta (aunque presumiblemente de 1907)- lleve el elocuente título de Le voyeur.

Estos datos demuestran que a partir de este tipo de mirada se determina, desde el punto de vista diegético, una forma canónica para introducir la (casi siempre) árida explicitud de la materia sexual -no exenta de justificación en este tipo de producciones-. Al igual que la pintura de finales del Quattrocento, que hace uso del mironismo (Ramírez 2003: 216-218) en tanto justificación de desnudos, el hardcore también se acoge a este recurso para detallar el coito, lo que facilita que se opere la identificación -secundaria según Metz (1979)- del espectador de la cinta con el personaje de la historia: "It is as if the spectator's ability to get into the act, through identification with the male performer who 'gets into' the woman, partially offsets the loss of his own direct exchange with the performing body of the woman" (Williams 1990: 78). En una tesitura semejante, Company afirma que el cine en tanto vivencia de la realidad se propone en sí mismo como un espectáculo voyeur, a diferencia del hard-core, que lleva al absurdo ese voyeurismo de pretender ver todo (1978: 43).

Si bien sus antecedentes se remontan hacia el siglo XVI, cuando el arte figurativo ya se había integrado al servicio de la iglesia ${ }^{24}$, la emergencia formal de la pornografía (del

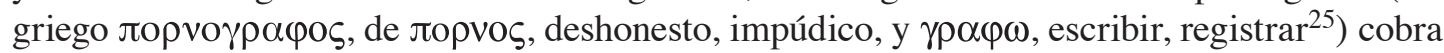
renovado vigor en la era de la cultura moderna de masas - la cual había propiciado la difusión de nuevos productos (novelas y revistas) existentes desde la época victoriana-, en buena parte gracias al impulso de la tecnología (videos y filmes) durante la segunda mitad del siglo XX (Kendrick en Williams 1990: 12). De hecho, la fuerza del género anida, con más fuerza que en ningún otro, en la exposición de este tipo de imágenes, como apunta Gubern: "la gratificación erótica se obtiene con la exposición de partes del cuerpo investidas de significado sexual, sobre todo los genitales" (1994: 40). De ahí que el hard-core escenifica el conocimiento y placer visual que responde a lo que Williams sumariza como el frenesí de lo visible ${ }^{26}$.

La explicitud que caracteriza a las imágenes de este género lleva a Jean Baudrillard a admitir que en la pornografía no existe un voyeurismo sexual sino un voyeurismo de la representación (de la exactitud), en donde lo que se pone en juego no es tanto el sexo como una realidad enfatizada (1989: 33-34), esto es, el lugar donde los signos -y sus referentes- son llevados a su límite de significación. Asimismo, la enfatización del efectoporno redunda en una hiperrealidad (fisiológica) que se adscribe a una época y a una cultura específicas cuyos más reveladores síntomas se exteriorizan constante y compulsivamente. Desde los talk-shows hasta los escaparates ambulantes en los que se reconfigura el cuerpo moderno prima la tendencia de mostrarlo todo, de expresarlo todo, de no dejarse nada guardado. Triunfo de la develación, la era finisecular -como suelen serlo, de crisis- postula la clausura del secreto: no hay sexualidad (ni siquiera la personal) a cuyo funcionamiento se asista en forma tan exacta -el presupuesto (tecnicista) es que el ojo de la cámara percibe mejor que el ojo humano- y tan cercana -tanto 
que "se confunde con su propia representación" (Baudrillard 1989: 34)-, pero al mismo tiempo demasiado lejana (su naturaleza no deja nunca de ser vicarial).

La pornografía se configura entonces como un catálogo de situaciones invariables y personajes estereotipados donde predominan imágenes de sexo explícito (y trivializado) repetidas hasta el infinito y articuladas desde una narración accesoria, pretextual. Precisamente es lo que separa a la mirada voyeurista de la pornográfica: esta última, en tanto abre las puertas de la intimidad de sus ejecutantes para que la observación sea plena, no deja el mínimo resquicio para el secreto: la mostración se cumple de modo total, excesivo. En este sentido, es el género que, a diferencia del resto de la tipología fílmica, no precisa del fingimiento narrativo de la situación: cada gesto, cada movimiento de sus intérpretes se realiza de forma auténtica, restringiendo las posibilidades de simulación ${ }^{27}$. Pero sobre todo, a ello se suma el carácter habitual de la suspensión de la prohibición de la mirada a la cámara en el momento de máximo placer sexual, donde el actor/actriz encara directamente al espectador-dinámica que invierte los términos del estatus de objeto de la mirada-. Por cierto que los alcances de este hecho imponen una reconsideración del lugar común de la cosificación o degradación del actor/actriz en tanto objeto de la mirada: la ecuación queda aquí subvertida y el espectador es quien pasa por tanto a ocupar la posición del objeto, en vista de que son los sujetos reales (los actores) quienes lo reducen a la condición de objeto-mirada paralizada (Zizek 2002: 183), solazándose de su situación de privilegio y excluyéndolo de su goce. Esta particularidad la constituye en la más franca, rotunda de todas las miradas -y la que, por tanto, precisa menos del escondite-. La mirada, pues, que se focaliza en la representación pornográfica sería la que se situaría a las antípodas de la contemplación voyeur.

\section{La mirada ausente (la imagen negada)}

Uno de los principios que definen la mirada voyeur es la ejecución de un acto esconderse- previo al acceso visual de una escena que de ordinario no pertenece al orden público. Por lo general tal escena se ha venido a identificar con lo que tiene que ver con la materia sexual (como la representación pornográfica, que hace referencia, ante todo, a una intimidad necesariamente ajena aunque menos furtiva). Sin embargo, no solo la sexualidad tiende a abstraerse de la esfera social e imaginaria: de la muerte -esto es, de su derivación inmediata, el cadáver- también se deslinda una prohibición, si cabe, más desplegada, aunque de otra índole.

Tanto la sexualidad como la muerte componen aquellos "estados frágiles en donde el hombre erra en los territorios de lo animal" en los que "las sociedades primitivas marcaron una zona precisa de su cultura para desprenderla del mundo amenazador del animal o de la animalidad, imaginados como representantes del asesinato o del sexo" (Kristeva 2000: 21). Sin pretender generalizar ni rehuir la diferencia de actitudes que cada sociedad y momento histórico llega a asumir, ambas instancias se definen como acontecimientos sobre los que, desde las civilizaciones más primitivas hasta las más industrializadas, se han puesto en cuestión prohibiciones o restricciones. El hombre, decía Georges Bataille, "es un animal que ante la muerte y ante la unión sexual se queda desconcertado, sobrecogido" (1997: 54). A nivel social, estos dos eventos terminan configurando su propio código ético -al cual se ajustan los tabúes que dictan lo que se considera representable y lo que no-. El tratamiento que se les da se viene a ejecutar a través de una operación de sublimación y/o de separación. Sin embargo, a pesar de que se proceda por la primera vía, la representación de la muerte -con mayor 
fuerza aun que la de la sexualidad- ha sido destinada al reino de la abyección, al ámbito de la impureza, de la contaminación: "Según la concepción de los antiguos, un cuerpo muerto hacía impuro cuanto le caía cerca; y no sólo a los hombres que lo tocaban o lo veían, sino a los dioses mismos. La visión de un muerto les estaba vedada" (Lessing 1992: 10). Esta actitud fundaría una tradición en la que también se inscribe el cristianismo -ya lo sentencia el Antiguo Testamento: el cadáver es una "maldición de Dios" (Deut.: 21: 22-23)-.

Incluso en una época como el siglo XVIII en el que Ariès define la actitud hacia la muerte como más próxima y atenuada, se impone una refinada suerte de prohibición patente en la ley de las XII Tablas en Roma o el Código Teodosiano- donde se propone una distinción entre el mundo de los vivos y de los muertos. Tal diferencia se materializa entonces con cambios infraestructurales en las ciudades, las cuales trasladan los cementerios a sus extrarradios con el fin de evitar la eventual perturbación que los difuntos pudieran causar a sus habitantes (2000: 34- 35). Se trata de una especie de alejamiento que se ve profundizado en otros niveles, como el lingüístico, cuya radicalidad ha llegado a generar, desde los antiguos (Lessing 1992: 36), circunloquios preferibles a su sola mención. Como ha enunciado Kristeva, "[e]l cadáver -visto sin Dios y fuera de la ciencia- es el colmo de la abyección. Es la muerte infestando la vida" (2000: 11), la inquietud que propiamente tiene que ver con lo que como presencia suscita se remonta unos cien mil años atrás, al paleolítico inferior, al hombre de Neanderthal, según lo hace constar desde entonces la existencia de sepulturas (Bataille 1997: 47) -que bíblicamente responden a una forma de purificación ["Le dará sepultura la casa de Israel, para purificar la tierra" [énfasis agregado] (Ez. 39: 12)]-. Sabidos son también los testimonios de tal tradición en los remotos orígenes de la cultura occidental, al respecto de lo cual la dramaturgia clásica ofrece un importante documento no desembarazado de la discusión al respecto pese al tono lírico que la compone: Antígona, cuyo conflicto se desencadena a raíz del edicto real que plantea una disparidad de exequias entre los dos hermanos abatidos entre sí en combate cuerpo a cuerpo, uno de ellos (Polinices) considerado traidor a su ciudad y por tanto indigno de enterramiento -la máxima afrenta de ultraje-: una práctica que aun -en algunas civilizaciones más que en otras- es rigurosamente mantenida.

La cultura visual conserva esos arcanos tabúes y registra la muerte y la sexualidad como constitutivas de la abyección aunque, a partir del momento en que el aparato fílmico las somete al dispositivo de la ficción, le concede su naturalización (desde un enfoque, en la generalidad del cine industrial, banalizado $)^{28}$. Pese a ello, la configuración de un imaginario prohibido habría de consignar los recelos que pesan respecto de cualquier presentación real de la muerte ante el horror que desde los primitivos continúa vinculándose al apego que insufla la vida y que promueve los procesos de ocultación sobrevenidos en torno a este hecho definitivo e irreversible: un horror que se suscita básicamente porque la exposición del cuerpo degradado resume la corrupción de ese mundo, en palabras de Bataille, del cual hemos salido (ya lo decía San Agustín, inter faeces et urinam nascimur) y al cual volvemos (1997: 60) ${ }^{29}$ : En otros términos, tal suceso vivifica la precaria condición que a lo largo del desarrollo histórico (y concretamente en la esfera de lo simbólico) el hombre ha sometido a la sublimación. Desde la Antigüedad Clásica, la representación de la muerte evitaba ser algo desagradable y relacionado con la descomposición del cuerpo (Martínez-Artero 2004: 28). A raíz del horror de una visión semejante se imponía una estilización del cadáver. Los antiguos griegos llegaron a evadir la presentación de la materia más resistente a la degradación (el esqueleto) y a decantarse por la figura de un hombre dormido: no es casualidad que hermanaran a la muerte con el sueño (Lessing 1992: 6). Sin embargo, 
como conjunto de valores, esta restricción imaginaria que alcanza trascendencia por el terror a la muerte y a todo cuanto la invoque (sus representaciones) no debería ser confundida con la iconoclastia, incluido el imaginario cinematográfico dominante anterior a Hitchcock ${ }^{30}$, que también asumió las reticencias de mostración del cadáver dentro de sus políticas de censura.

El arte, dice Debray, nace funerario (1994), y si bien durante el realismo no faltó quien intentara capturar esa fenomenología del morir (Nochlin 1991: 52), la ya sabida convención con el referente matiza lo que se podía interpretar como la dureza de las representaciones. La mostración, en cambio, no ficcional, de los cuerpos huecos, vaciados de toda sustancia, ha sido una pauta general que se plasma, al menos en Occidente, como irremisible temor, especialmente en las ocasiones en que surge a partir del efecto de una acción violenta y/o repentina -por tal razón, cuando sobreviene de modo inesperado en las zonas públicas se suele proceder al cubrimiento de los cuerpos, del mismo modo que, siguiendo a Bataille, los primitivos extendían la ocultación hasta de los huesos, porque aun su blancura invocaba la amenaza de una violencia opuesta a la vida del trabajo (1997: 51), es decir, contraria a la actividad cotidiana-. El otro (re)cubrimiento del cadáver, el definitivo -la tumba-, trae consigo, como aprecia Didi-Huberman, una angustia que "impone en mí la imagen imposible de ver de lo que me hará igual y el semejante de ese cuerpo en mi propio destino futuro de cuerpo vaciándose, yaciendo y desapareciendo rápidamente en un volumen más o menos parecido [...], quedar librado a la cuestión de saber (de hecho: de no saber) en qué se convierte mi propio cuerpo, entre su capacidad de constituir un volumen y la de ofrecerse al vacío" (1997: 20) -una angustia, pues, que ha intentado suturarse por medio de dos vías: lo que el teórico francés llama el ejercicio de la tautología o la indiferencia ("lo que veo es lo que veo") que limita lo visible a la evidencia, y el ejercicio de la creencia, donde lo visual es trascendido por la convicción en la existencia de algo superior (1997: 21-26).

La muerte, así pues, ha permitido generar las más complejas disquisiciones vinculadas a -mejor aun, fundantes de- los ámbitos disciplinarios más heterogéneos, desde la medicina hasta la poesía, que apuntan, cada una desde su perspectiva, a explicar un incidente de compleja asimilación, de inútil imaginación, independientemente de que se suscriba por causas naturales, como lo expresaba Bertrand Tavernier: "Lo real de la muerte escapa a toda figuración" (Company en Riambau y Torreiro 1992: 83). Su filme Death Watch (1979) enmarca la acción en una sociedad futurista que había logrado desterrar el perecimiento pero seguía indefectiblemente aferrada a la escopofilia. De ahí la imposibilidad de su protagonista Roddy para registrar, desde sus ojos-cámara, la inclemente faena de la agonía (de quienes no lograban eludirla) -aun cuando la cercanía construida (básicamente a partir de la mirada) con una cada vez más decrépita Katherine Mortenhoe alcanzara los límites de una identificación que lo llevaría a repudiar su propia visión hasta acometer la estrategia de Edipo-. Es así como adquiere sentido ese comienzo-final de los cuatro planos de tumbas en medio de las cuales una niña salta a la cuerda, como si con ello Tavernier quisiera asegurar que "la única posible inscripción significante sobre la muerte se encuentra en las lápidas de los camposantos" (Company en Riambau y Torreiro 1992: 84).

Entonces si la pregunta - con la que Camus introduce las primeras líneas de Le mythe de Sisyphe (1942) - en cuanto a que si la vida merece la pena vivirse constituye el único problema auténtico de la filosofía, lo que acontece sobre la muerte adquiere una magnitud mayor en momentos de la historia donde se producen coyunturas que exceden toda comprensión, ocasiones que superan cualquier argumentación racional: las hecatombes. 
En tanto tales, estas conllevan la posibilidad de desencadenar la inexorable recuperación de los hechos avergonzantes, paralelo a la preservación de la memoria histórica a través de la elevación de monumentos o la develación de placas que se proponen honrar a las víctimas.

Una problematización básica sobre tales obras conmemorativas revela el carácter cuestionable de su naturaleza -más que de sus corolarios éticos (los propósitos) - en el sentido de que contienen el problema de la aprehensión del acaecimiento. En efecto, la dificultad de integrar, en un solo monumento, un evento elementalmente desbordante supone el silenciamiento de "sus innumerables voces individuales, reduciendo su espantosa complejidad a una singularidad comprensible, fundiendo sus muchedumbres de nombres y de rostros en un único emblema sin nombre ni rostro" (Manguel 2003: 308). Lo que en última instancia se desprende de ello es la imposibilidad de representar el horror; esto es, que la atrocidad de algunos sucesos excede todo carácter de representabilidad, lo cual viene a dificultar su sistematización.

Estas ocasiones en las que la realidad misma se revela tan pavorosa -lo que McQuire llama las intolerable memories (1998)- vuelven impracticable la sola posibilidad de relatar el hecho. Sucede, ciertamente, con las palabras -tras el Holocausto, Adorno llegó a rechazar cualquier tentativa de escribir poesía lírica en sintonía con el silencio que emanaba de la muerte-, pero llega a su límite con la visualidad, a partir de propuestas interesantes como la de un documentalista del prestigio de Claude Lanzmann ${ }^{31}$. La idea que subyace en el flujo que discurre durante más de nueve horas en su texto fílmico Shoah (1985) es que hay una visión absoluta, la existencia de un hecho trascendental que, en tanto se manifiesta -en su caso, a través de la recreación verbal (la entrevista) - como evidencia, desborda el imaginario social -es más, excede incluso a la muerte misma-. De modo que, antes de que la autentificación de lo abominable recurra directamente a la visualidad -de mayor objetividad en principio que la narración (Català 2000: 113), más analógica que simbólica-, no queda otro camino que acogerse al dispositivo de la operación oral. Por eso Lanzmann presenta el suceso en cuestión desde el procedimiento opuesto a la sobrecarga tautológica de Magritte, postulando una pluralidad de subjetividades -que el monumento o la placa se revelan incompetentes para registrar-donde no hay perífrasis eufemísticas que valgan. Acaso lo mismo que escribe Borges en El jardín de los senderos que se bifurcan (1941) -“[o]mitir siempre una palabra, recurrir a metáforas ineptas y a perífrasis evidentes, es quizá el modo más enfático de indicarla" (1985: 114) - pueda también ajustarse a la fenomenología de las imágenes, subrogadas en formas de expresión que no son propias del medio fílmico: las palabras y los silencios. Su uso se ejerce como una especie de rodeo que prácticamente gira alrededor del hecho -porque quizá esa sea su esencia-, sin que a pesar de todo pueda alguna vez llegar a aprehenderlo, a abarcarlo, a mostrarlo en sus contornos, sus dimensiones, sus texturas - acaso prerrogativa de la imagen-.

En contraste con la mayor parte de los materiales fílmicos (especialmente de ficción) que incluyen obscenas cifras, la trascendencia del acontecimiento es tal que impone en el documentalista una resistencia a reproducir (ni siquiera a partir de reconstrucciones visuales y menos aun de las imágenes de $\operatorname{archivo}^{32}$ ) cualquier estampa alusiva: el silencio de una expresividad aquí más elocuente que el tropel tan vinculado hoy tanto con lo imaginario a lo que se aúna la privación de una banda sonora es a duras penas quebrado por la palabra ${ }^{33}$. $\mathrm{Y}$ es que, como sostiene Joan Carles Mèlich en el postfacio de Shoah, una pedagogia de la memòria, la paradoja de Lanzmann es que "l'inexpressable només es pot expressat [sic] a través del silenci" (en Torner 2002: 326): si la contundencia de la muerte es, de suyo, irrepresentable, no se justifica menos en un acontecimiento de tal magnitud que no hace sino 
ensanchar, como decía Primo Levi, el foso "entre las cosas tal y como eran 'allí', y tal y como se representan en la imaginación común, alimentada por los libros, las películas y los mitos aproximados" (en Didi-Huberman 2004: 126) ${ }^{34}$. La historia, entonces, no solo se estructura con base en los procedimientos visuales sino también en lo que emerge de la memoria: quizá por eso Lanzmann no duda en presentar testimonios que no escatiman en datos que en un documento de otra naturaleza podrían parecer irrelevantes, como el clima, el paisaje, los olores, las sensaciones que rodean pero no abordan un cataclismo que excede a la colectividad.

A pesar de todo, este tratamiento de no mostración de las imágenes abre la posibilidad de que el espectador consuma el texto a partir de la curiosidad, a la manera de un agujero que descuenta el objeto de deseo escópico -sobre todo en un caso que, aparte de que deje traslucir la certidumbre del frustrado proyecto racional, instaura un no-poder-ver frente a la instauración del ver que despierta el voyeurismo ${ }^{35}$ : dos configuraciones que operan sobre un mismo terreno de prohibición (Català 26/02/04) -. El voyeur choca frontalmente con el interdicto implícito de presentación de los cuerpos resultantes de situaciones de catástrofe.

Así se explica que, fuera del debate suscitado en torno a su conveniencia o impertinencia, representaciones como las cuatro fotografías de uno de los crematorios de Auschwitz-Birkenau tomadas por un miembro del Sonderkommando (la resistencia polaca) [sic] hayan merecido, entre otros atributos, el de fomento del "voyeurismo y goce del horror" (Pagnoux en DidiHuberman 2004: 88). El conflicto surge porque se trata de imágenes tangencialmente opuestas a las anteriores -las que revisten connotaciones sexuales (vitales, en última instancia)-, pertenecientes a la auténtica intimidad -porque al final de cuentas no existe nada más privado, más personal que la propia muerte-. Por eso sobre ellas pesa una condena que se resiste a la mostración -ya que, como dice Lanzmann, "there are some things that cannot and should not be represented" [énfasis agregado] (1994b: 14). En última instancia, hay cosas sobre las que pesa una dificultad de mostración incluso porque se duda de su carácter de representabilidad-. Lo que subyace, en definitiva, es una resistencia vinculada con las más atávicas razones que se niegan a la visualización a partir del argumento de la dificultad extrema de sostener la mirada -la misma razón que constituye, paradójicamente, su máximo acicate-.

\section{Cierre}

Los tipos de mirada que aquí se identifican como proscritos se focalizan menos en el frío acto de percepción que en el goce que es capaz de suscitar la imagen misma. Esta le permite al sujeto reflejarse, identificarse, problematizar sobre un acto de visión que -como obsesión pigmaloniana en buena parte guía de la historia del arte occidental (Stoichita 2006) - termina inexorablemente dirigido al cuerpo. Las formas en que se construye -percibidas siempre como reales y vivas- tienen la propiedad de despertar el deseo del espectador: "al percibir el cuerpo como algo real y vivo, somos capaces de desearlo", apunta Freedberg (1992: 367). Esta relación entre la mirada con la curiosidad y/o el deseo está a la base de la prohibición de las imágenes -por eso el contacto visual instaura un tabú, como se constata en infinidad de culturas que desaprueban la mirada fija en tanto revela un exceso de intimidad, de sexo o de expresión demasiado libre de las emociones (Davis 1973: 85)-. En este sentido, Hall se preguntaba "why 'the look' is so powerfully inscribed by the play of desire, so that no look is ever satisfying, but always excites the drive to look more, to see beyond, as if to gaze enough would be to see what is forbidden, what should not be shown or seen" (en Evans y Hall 2003: 313). 
La construcción social de las imágenes suele obviar cierta tipología visual confinada a lo que se ha formalizado como abyección, en tanto al incidir sobre variaciones del cuerpo donde intervienen articulaciones complejas de la mirada pone en juego el deseo y la muerte. Pero es así como el hombre, en su calidad de ser deseante, encuentra en la imagen, aun la más prohibida, la oportuna posibilidad de proyección de ese objeto sustitutivo: empeño frustrado que se conforma -no tiene otro remedio- con la divagación, con el regodeo acompasado y minucioso del ojo por la superficie inerte de la representación, tan inalcanzable como su propio referente: todas son miradas que comparten la ambivalencia de una satisfacción condenada a su perpetua postergación.

\section{Notas}

1. Que, en su misma interiorización, es una impureza que se confunde con la culpabilidad ya existente en el plano moral y simbólico de la Biblia: una fusión que, "con la abominación más objetal, más material, se constituirá una nueva categoría: el Pecado” (Kristeva 2000: 155).

2. No siempre el adentro da cobijo y seguridad frente a lo externo que se suele presentar como desconocido e inseguro, como demostró Freud. En los retratos de fin de milenio empieza a aflorar un sujeto descrito desde su proceso orgánico interno. A partir de una sumersión en los adentros fisiológicos, por mucho tiempo prerrogativa de las ciencias médicas, artistas visuales contemporáneos han venido proponiendo una idea del cuerpo que renuncia a ser la sede del alma para convertirse en una obra de arte. En algunas de las video instalaciones de Mona Hatoum, como Corps Étranger (1994), se exhibe el resultado de la introducción de una microcámara de video (scanner) que desciende desde el esófago hasta el estómago de la propia artista -donde lo inusual de la percepción dificulta el autorreconocimiento al que alude el adjetivo del título-. El resultado es "un espacio audiovisual inquietante [...] El interés de Hatoum por los entornos absorbentes se desdobla: el usuario se ve inmerso en la cabina de visionado y más adelante en un espacio biológico horrible, iluminado sólo por el ojo tecnológico. El cuerpo es a la vez injuriado y revelado", explica Alex Galloway (s. f.: 5). Las performances del australiano Sterlac también se inscriben en esta tendencia de experimentación con las nuevas tecnologías -avenidas por tanto a la noción de cyborg (Haraway)- en el mismo deseo expreso de Hatoum por adentrar la mirada en los orificios orgánicos. Pero la revelación de lo interno en las artes no se limita al funcionamiento meramente biológico. En su filme futurista Hasta el fin del mundo (1991), Wim Wenders vuelca la mirada hacia lo interior y la liga a aquello que descoloca, que trastorna, porque implica un viaje hacia los destinos más recónditos y ominosos del hombre mismo: el inconsciente.

3. "El deseo ocular ha preocupado a aquellos", dice Martin Jay, "que querían privilegiar la mirada como el más noble de los sentidos, puesto que parece minar el desinterés de la contemplación pura. En el discurso anti-ocularcéntrico francés, es precisamente la inevitabilidad de tal deseo impuro lo que socava la pretensión de que el ojo es desapasionado, frío y neutro" (en Guash en Brea 2005: 63).

4. Desde el siglo XII hasta el XVII, la mayor parte de los tratados de demonología denuncian las prácticas culpables de quienes solicitaban la protección del diablo mediante artes como la catoptromancia: "la imagen reflejada en el espejo puede provocar un estado de hipnosis o de trance; el brillo del instrumento impide al que lo mira fijarse en los objetos exteriores, y su atención, volcada hacia el interior, anulada, percibe intuiciones sobrenaturales, a veces procedentes de Dios, pero, con más frecuencia, obra del demonio" (Melchior-Bonnet 1996: 203).

5. En realidad, se estaría hablando propiamente de una identificación en el sentido en que el inconsciente deseo de L. B. Jefferies, que rige su actividad escópica, es que el despiadado asesino lleve a cabo lo que él, en su fuero interno, no se atreve a hacer con Lisa, su pareja. 
6. Aunque no en todas las épocas el espejo -el reflejo- ha tenido el mismo sentido: en el siglo XVII, por ejemplo, alentó el proceso de introspección (Melchior-Bonnet 1996: 155).

7. Es decir, como a un ídolo, según Mitchell: “An idol, technically speaking, is simply an image which has an unwarranted, irrational power over somebody; it has become an object of workship, a repository of powers which someone has projected into it, but which in fact does not possess" (1987: 113).

8. A través de la ekfrasis, un género literario perfectamente codificado y establecido que consiste en la "descripción por medio de textos en prosa de obras de arte que evocan en general temas mitológicos" (Dubois 1986: 128).

9. Según Laura Mulvey, “[l]as convenciones de los films [sic] dominantes focalizan la atención sobre la forma humana. Escala, espacio, narraciones, todas son antropomorfas. Aquí, la curiosidad y el deseo de mirar se mezclan con la fascinación hacia el parecido y el reconocimiento" (1988: 6).

10. Aunque una (secular) variación de la ecuación redunda en un funcionamiento a la inversa -a partir de un equiparamiento con el auténtico creador (el hombre), como ocurre en la mitología grecolatina con los singulares personajes dominados por impulsos típicamente humanos-.

11. El mito propone que, en tiempos casi inmemoriales, la humanidad se dividía en tres tipos de especímenes: machos, hembras y unos seres andróginos morfológicamente constituidos como una adición de los otros dos géneros, pero Zeus decidió cortarlos a la mitad para debilitarlos y aumentar el número de habitantes a fin de que poblaran la tierra: desde entonces, estas criaturas escindidas están condenadas a una incesante búsqueda de su antigua mitad para recuperar la unidad perdida (189c-193d).

12. Aparte de ello, cabe considerar las nuevas tecnologías de la imagen con las que Baudrillard reactualiza su pensamiento y replantea la especificidad de otras superficies, las cuales no tienen nada que ver con la narcisista del espejo, como la moderna pantalla de video (cuya eclosión se produce en la posmodernidad). Según él, se trata de una pantalla de refracción estática que viene a reemplazar al estadio del espejo, pues ya no se utiliza para interpretar o contemplarse, sino que se limita a funcionar como un acto de inserción sobre ella misma (en Anceschi et al. 1989: 31), es decir, a captar superficial e indiferentemente el mundo.

13. Igual que el nombre de la ninfa que se enamora de Narciso, la cual, tras el rechazo, en la versión de Ovidio, se demacra hasta disiparse. De ella solo queda una voz lastimera -con lo que el relato contiene dos alusiones a los reflejos: las aguas, que son el reflejo de la imagen, y el eco, reflejo de la voz-.

14. Tras la revolución industrial y las reproducciones en masa, la civilización posmoderna ha naturalizado la creación de dobles individuales -la clonación de seres vivos (la oveja Dolly) - o colectivos -las simuladas ciudades (towns) a pequeña escala-. Por cierto que la imitación no se da solo en ciudades "verdaderas", sino también fantásticas, como Disneyworld, de cuyas travesías fabulosas escribe Eco: "El placer de la imitación, ya lo sabían los antiguos, es uno de los más connaturales al espíritu humano, pero aquí además de gozar una imitación perfecta se goza del convencimiento de que la imitación ha alcanzado su punto culminante y de ahora en adelante la realidad será siempre inferior" (1999: 52).

15. Nichols, que plantea esta presencia en términos de estereotipos culturales, amplía la alteridad bajo el síntoma de la intranquilidad, rechazo o ansiedad: "El estatus del Otro [sic] como proyección o fabricación [...] supone que la ficción clásica tiene una enorme dificultad para representar otras culturas fuera de su función dentro de un sistema de oposición e identidad" (1997: 261). 
16. Es una voz que no tiene equivalencia con ninguna otra en castellano: "son todos insuficientes porque no incluyen como lo hace el término alemán este sentido de transformación en lo contrario: lo familiar que ha devenido pavoroso, lo Heimliche trastocado en Unhemilche" (Braunstein 1981: 195). Las traducciones -como siempre, traidoras- de los versos 332-333 de la tragedia griega, también conocidos como "elogio del hombre", no siempre llegan a coincidir en el uso de la palabra clave (deinótaton o deinóteron): mientras Hölderlin la interpreta como monstruoso -"Mucho es lo monstruoso. Nada sin embargo que sea más monstruoso que el hombre"-, Estiú modifica el sentido de la frase al trasladar la locución como pavoroso. Otras ediciones, como la utilizada -Alamillo para Gredos-, emplea el vocablo admirable -lo que supone, como establece Braunstein, un "deslizamiento semántico bastante común que hace de lo terrible algo grandioso y superlativo y, por eso, algo admirable” (1981: 194-195)-.

17. Como disensión al escrito de Ernst Jentsch, que, con base en el relato de E.T.A. Hoffmann, Der Sandmann (1815), interpretaba el concepto básicamente como falta de orientación.

18. Que no ve lo siniestro como una expresión negativa, sino como una posibilidad de liberación de las represiones: "The uncanny [...] confronts one with a world in which the familiar and unfamiliar, the canny and the uncanny, are in a state of uneasy alliance, suggesting the possibility of intervention, of changing a part of the world and the self, a moment of desymbolization where there is a shift of the old order and a chance to resymbolize, to create fresh symbols" (en Collier y Davies 1990: 281).

19. Con el matiz incluido por el propio Freud, que consideraba que "[t]he sexuality lies less in the content of what is seen than in the subjectivity of the viewer" (Rose 1986: 227).

20. En un reportaje televisivo retransmitido en España titulado "El placer de mirar", los dos sujetos entrevistados, uno con 3 y otro con más de 20 años en el ejercicio, manifestaron que su actividad únicamente se limitaba a mirar. Pese a ello, hubo circunstancias -realmente excepcionales- en que su participación vino a contar con la connivencia tácita de la pareja observada, con lo que se sugería que el voyeur terminaba cumpliendo una especie de "función social" exclusivamente para las ocasiones en las que el acto sexual se había visto imposibilitado (•Rec, Tele5, 19/09/03) -una intervención que, sin embargo, aseguraba no sólo la prolongación del acto de los otros, sino de su propio goce-.

21. Lo ratifica la ficción fílmica: en The Prowler (1951) de Joseph Losey, el auténtico peligro no está en el desconocido mirón, sino en un personaje delineado que trabaja al servicio de la protección ciudadana: Webb Garwood, el agente frustrado y corrupto para cuyos abusos se sirve del nunca identificado fisgón como coartada -pues no hay mayor voyeur que quien funge de guardián, como lo prefigura en la primera secuencia, cuando sorpresivamente se asoma a la ventana de su futura presa, Susan Gilvray-: él es el auténtico merodeador. Varias décadas después, Patrice Leconte en Monsieur Hire (1989) ahondaba en este tratamiento tendiente a la exculpación a través de la estimulación identificatoria que propicia la perspectiva desde la que se cuenta con esta figura, protagónica y desolada -la joven de quien se enamoraba (tras haberse dedicado a atisbarla por la ventana) se valía de su propensión visual para incriminarlo en un crimen que perjudicaba directamente al chico del que estaba enamorada-.

22. Según estos datos, procedentes de la Sociedad Sexológica de Madrid, son pocos los que se consideran enfermos, y los que se reconocen como tales tratan de ocultarlo. En contraste con el titular ("Sólo el 1 por 100 de los exhibicionistas y mirones recibe tratamiento psicológico"), que singularizaba el fenómeno, la noticia incluía declaraciones naturalizadoras por el portavoz del teléfono de información sexual Sex-inform: "Todos somos un poco mirones y exhibicionistas [...], algo totalmente normal hasta que se convierte en el único modo de llegar al placer sexual y pasa a ser una patología” ( $A B C, 05 / 08 / 91$ : s. p.).

23. Los textos que han problematizado sobre la relación entre visión y sexualidad es inconmensurable, pero cabe hacer una mención rápida a un texto de elocuente título, Histoire de l'œil (1928) de Lord 
Auch, seudónimo de Georges Bataille. Entre las peculiaridades más celebradas de esta novela radica que la mirada sobre lo íntimo se narra a partir de una serie de símbolos ovoidales aislados que están en función de una cadena metafórica: los huevos, los testículos, el ojo -sucesión que, como comenta Barthes, no tiene jerarquía: no es, por tanto, una historia profunda; es una serie que se da en superficie y que no remite a ningún significado (1967: 287)-. Pero es significativo que el ojo sea elemento último que cierra el camino creciente de transgresiones más allá del cual no existe nada, el eje que articula no sólo la sexualidad, sino también la muerte, en realidad, leit-motif del género -pues la pornografía, como propone Sontag, es la erótica de la agonía (1985: 71)-.

24. En virtud de que los sentidos se consideraban proclives a la excitación a través del arte, la censura intervino a fin de adoptar las medidas posibles para que sus obras no excitaran los sentidos equivocados (Freedberg 1992: 413). Muestras de ello son los grabados Marte, Venus y Vulcano (1543) de Enea Vico, los más explícitos Pan y Siringa (1516) -del que figura, aparte del original, una copia a la que los censores superpusieron como añadido las hojas de un árbol que cubrían el miembro en erección del dios- o los Modi (1524?): ambos de Marcantonio Raimondi, aunque de esta serie solo se conservan fragmentos por orden (e ira) de Clemente VII. La tendencia por este tipo de representaciones parece resurgir más tarde, en el siglo XVIII, en el que Berger menciona la existencia de una categoría muy especial de cuadros pornográficos privados (2002: 65).

25. De esta misma raíz proviene $\pi$ - $\rho v \varepsilon \imath \alpha$, prostitución o fornicación, lo que explica el desacertado sentido de la vigésima segunda edición del Diccionario de la Lengua Española de la Real Academia, el cual define el término pornografía como "tratado acerca de la prostitución".

26. "[T]his frenzy is neither an aberration nor an excess; rather, it is a logical outcome of a variety of discourses of sexuality that converge in, and help further to produce, technologies of the visible" (Williams 1990: 36).

27. A no ser de que se tomen en cuenta las posibilidades elusivas de la fisiología femenina. El placer físico masculino se representa ineludiblemente mediante la erección y la eyaculación (conocido en la jerga de la industria como money shot), pero se dificulta cuando se trata de mostrarlo en la mujer, porque en su caso el orgasmo no tiene lugar preciso (Williams 1990: 49).

28. Justamente por el conocimiento previo de su carácter de ficción: ligada a la violencia, la muerte tiene una alta cuota de visualización, sobre todo en filmes que trivializan el acontecimiento; mientras que -ya lo dice Foucault-, sólo como discurso, la sexualidad se ha venido multiplicando antes que rarificando desde hace tres siglos (1987: 67). Desde una estética del realismo, la industria audiovisual se ha propuesto el desarrollo de fórmulas abocadas a la presentación de la sexualidad -el porno duro, que ha sido parangonado con el documental-, pero la muerte no tiene representación correspondiente (a no ser el género snuff, que por un lado prioriza la violencia y por otro su prohibición no le permite inscribirse, al menos en igualdad de condiciones en el circuito comercial, con el hard-core).

29. Para estos pueblos, "[e]l muerto es un peligro para los que se quedan; y si su deber es hundirlo en la tierra, es menos para ponerlo a él al abrigo, que para ponerse ellos mismos al abrigo de su 'contagio'. La idea de 'contagio' suele relacionarse con la descomposición del cadáver, donde se ve una fuerza temible y agresiva” (Bataille 1997: 50).

30. En concreto, cuando la normativa del llamado Código Hays reprimió la mostración de los cadáveres, de manera tal que durante un buen tiempo alimentó el llamado pudor clásico en el sistema retórico hollywoodense (Sánchez-Biosca 1995: 183- 184). 
31. Habría que matizar con que esta posición ha suscitado debates en torno a lo que puede -o debe- ser expresado o no. Georges Didi-Huberman está convencido de que la no representabilidad esgrimida por Gérard Wajcman, Élisabeth Pagnoux y el mismo Lanzmann es una idea radical que termina conformando un discurso totalizante, absolutista -según su posición, el hecho de que no haya imágenes de campos de concentración (lo que es históricamente falso) no conduce a la deducción de que no hay imágenes de la Shoah- (Didi-Huberman 2004: 142).

32. Sostiene Lanzmann que si se hubiese topado con con un documento gráfico real de las SS que mostrara cómo 3.000 judíos -hombres, mujeres y niños- eran gaseados en el crematorio de Auschwitz no sólo se hubiera negado a presentarlo sino que lo habría destruido (1994b: 14).

33. Lo que no significa una ausencia de dificultades: "Es algo que no se puede contar", zanja casi de entrada Simón Srebnik, superviviente del segundo período del exterminio en el campo de Chelmno, coincidente con Simha Rottem en uno de los testimonios finales del film: "Estoy convencido de que la lengua humana es incapaz de describir el horror que nosotros conocimos dentro del gueto".

34. Razón por la cual filmes como Schindler's List (1994) de Steven Spielberg (“[i]n a way [...] a kitsch melodrama" según Lanzmann 1994b: 14) se construyen como miradas impertinentes de un hecho desbordante (el Holocausto visto a través de los ojos de un alemán).

35. La confrontación entre ambas formas de mirar queda manifiesta en la lúcida reflexión de Juan Antonio Ramírez en torno a dos de las mayores obras pictóricas de la humanidad, cuando propone Étant donnés: $1^{\circ}$ la chute d'eau $2^{\circ}$ le gaz d'éclairage (1944-66) de Marcel Duchamp como una inversión del considerado cuadro más célebre del siglo XX, Guernica (1937) de Picasso, un encargo del gobierno republicano que se convirtió en un homenaje a la masacre de civiles y heridos en el pueblo vasco como resultado del bombardeo de los nazis. Dice el autor: "frente al gran lienzo mural (para la contemplación colectiva), la aproximación intransferible del mirón individual; frente a la naturaleza 'edificante' del arte (denuncia de la crueldad sanguinaria de un hecho bélico), afirmación del deseo libidinal individualizado; frente al oscuro tremendismo (blanco y negro), el espléndido colorido de un paisaje brillantemente iluminado; frente a la deformación expresionista-cubista de los cuerpos, el realismo desaforado de los objetos tridimensionales" (2000: 238).

\section{Bibliografía}

Anceschi, Giovanni et al. 1989. Videoculturas de fin de siglo. $2^{\mathrm{a}}$ ed. Madrid: Cátedra.

Ariès, Philippe. 2000. Historia de la muerte en Occidente. Barcelona: El Acantilado.

Aumont, Jacques. 2002. La imagen. Barcelona: Paidós.

Barthes, Roland. 1967. Ensayos críticos. Barcelona: Seix Barral.

Bataille, Georges. 1997. El erotismo. $4^{\mathrm{a}}$ ed. Barcelona: Tusquets.

2003. Historia del ojo. $8^{\mathrm{a}}$ ed. Barcelona: Tusquets.

Baudrillard, Jean. 1989. De la seducción. $5^{\text {a }}$ ed. Madrid: Cátedra. 
Berger, John. 2002. Modos de ver. $7^{\text {a }}$ ed. Barcelona: Gustavo Gili.

Benjamin, Walter. 1973. Discursos interrumpidos I. Madrid: Taurus.

Braunstein, Néstor (coord.). 1981. A medio siglo de El malestar en la cultura de Sigmund Freud. México: Siglo XXI.

Brea, José Luis (ed.). 2005. Estudios visuales. La epistemología de la visualidad en la era de la globalización. Madrid: Akal.

Borges, Jorge Luis. 1985. Ficciones. Barcelona: Planeta-DeAgostini.

Camus, Albert. 1963. El mito de Sísifo / El hombre rebelde. $4^{\mathrm{a}}$ ed. Argentina: Losada.

Clair, Jean. 2007. De immundo. Madrid: Libros Arena.

Collier, Peter y Judy Davies. 1990. Modernism and the European Unconscious. Oxford: Polity Press.

Davis, Flora. 1976. La comunicación no verbal. Madrid: Alianza.

Debray, Régis. 1994. Vida y muerte de la imagen. Historia de la mirada en Occidente. Barcelona: Paidós.

Didi-Huberman, Georges. 1997. Lo que vemos, lo que nos mira. Buenos Aires: Manantial. 2004. Imágenes pese a todo. Memoria visual del Holocausto. Barcelona: Paidós.

Dubois, Philippe. 1986. El acto fotográfico. De la representación a la recepción. Barcelona: Paidós.

Eco, Umberto. 1999. La estrategia de la ilusión. $3^{\mathrm{a}}$ ed. Barcelona: Lumen.

Evans, Jessica y Stuart Hall. 1999. Visual Culture: the Reader. London: Sage.

Freedberg, David. 1992. El poder de las imágenes. Madrid: Cátedra.

Freud, Sigmund. 1973. Introducción al narcisismo y otros ensayos. Madrid: Alianza.

1975. Tres ensayos sobre teoría sexual. $3^{\mathrm{a}}$ ed. Madrid: Alianza.

1976. Lo siniestro. Argentina: López Crespo. 
2004. El malestar en la cultura. Madrid: Alianza.

Foucault, Michel. 1987. Historia de la sexualidad. La voluntad de saber. $14^{\mathrm{a}}$ ed. Madrid: Siglo XXI.

2001. Las palabras y las cosas. $30^{\mathrm{a}}$ ed. México: Siglo XXI.

Galloway, Alex. s.f. "Un informe sobre ciberfeminismo. Sadie Plant y VNS Matrix: análisis comparativo". http://members.fortunecity.es/chusaon/un_informe_sobre_ ciberfeminismo.htm (05/05).

Gubern, Román. 1994. La mirada opulenta: exploración de la iconosfera contemporánea. $3^{\mathrm{a}} \mathrm{ed}$. Barcelona: Gustavo Gili.

1998. El simio informatizado. $3^{\mathrm{a}}$ ed. Madrid: Fundesco.

2004. Patologías de la imagen. Barcelona: Anagrama.

Hoffmann, E. T. A. 1976. El hombre de la arena. Argentina: López Crespo.

Kristeva, Julia. 2000. Poderes de la perversión. $4^{\mathrm{a}}$ ed. México: Siglo XXI.

Lacan, Jacques. 1981. Seminario 1: Los escritos técnicos de Freud. Barcelona: Paidós.

1999. Seminario 11: Los cuatro conceptos fundamentales del psicoanálisis. Argentina: Paidós.

Lanzmann, Claude. 2003. Shoah. Madrid: Arena.

Lessing, Gothold Ephraim. 1992. La ilustración y la muerte: dos tratados. Madrid: Debate.

Manguel, Alberto. 2003. Leer imágenes. Madrid: Alianza.

Martínez-Artero, Rosa. 2004. El retrato. Del sujeto en el retrato. España: Montesinos.

McQuire, Scott. 1998. Visions of Modernity. London - Thousand Oaks - New Delhi: Sage.

Melchior-Bonnet, Sabine. 1996. Historia del espejo. Barcelona: Herder.

Metz, Christian. 1979. El significante imaginario. Barcelona: Gustavo Gili.

Miller, Jonathan. On Reflection. 1998. London: The National Gallery Publications Limited. 
Mitchell, W. J. T. 1987. Iconology. Image, Text, Ideology. Chicago - London: The University of Chicago Press.

Mulvey, Laura. 1998. Placer visual y cine narrativo. Valencia: Fundación Instituto Shakespeare.

Nead, Lynda. 1998. El desnudo femenino. Madrid: Tecnos.

Nichols, Bill. 1997. La representación de la realidad. Barcelona: Paidós.

Nochlin, Linda. 1991. El realismo. Madrid: Alianza.

Nochlin, Linda. 1994. The Body in Pieces. The Fragment as a Metaphor of Modernity. Great Britain: Thames \& Hudson.

Ovidio. 1990. Metamorfosis (Vol. I, Libros I-V). 4ª ed. Madrid: Consejo Superior de Investigaciones Científicas.

Platón. 1982. El banquete. $11^{\text {a }}$ ed. Buenos Aires: Aguilar.

Portús, Javier (ed.). 1994. El retrato en el Museo del Prado. Madrid: Anaya.

Ramírez, Juan Antonio. 2003. Edificios-cuerpo. Cuerpo humano y arquitectura: analogías, metáforas, derivaciones. Madrid: Siruela.

Ramírez, Juan Antonio. 2000. Duchamp. El amor y la muerte, incluso. $3^{\mathrm{a}}$ ed. Madrid: Siruela.

Riambau, Esteve y Casimiro Torreiro (eds.). 1992. La vida, la muerte. El cine de Bertrand Tavernier. Valencia: Filmoteca de la Generalitat Valenciana.

Rose, Jacqueline. 1986. Sexuality in the Field of Vision. London: Verso.

Sánchez-Biosca, Vicente. 1995. Una cultura de la fragmentación. Pastiche, relato y cuerpo en el cine y la televisión. Valencia: Filmoteca de la Generalitat Valenciana.

Sófocles. 2000. Tragedias. Madrid: Gredos.

Sontag, Susan. 1985. Estilos radicales. Madrid: Muchnick.

Starobinski, Jean. 2002. El ojo vivo. Valladolid: Cuatro.

Stoichita, Victor I. 2006. Simulacros. El efecto Pigmación: de Ovidio a Hitchcock. Madrid: Siruela. 
Torner, Carles. 2002. Shoah: una pedagogia de la memòria. Barcelona: Proa.

Walker, John A. y Sarah Chaplin. 2002. Una introducción a la cultura visual. Barcelona: Octaedro.

Williams, Linda. 1990. Hard Core. Power, Pleasure and the Frenzy of the Visible. London -Sydney - Wellington: Pandora Press.

Zizek, Slavoj. 2002. Mirando al sesgo. Una introducción a Jacques Lacan a través de la cultura popular. Barcelona: Paidós.

\section{Hemerografía}

ABC. 1991. "Sólo el 1 por 100 de los exhibicionistas y mirones recibe tratamiento psicológico". 05/08: 48.

Català Domènech, Josep Maria. 2000. “Ut poesis pictura”. Anàlisi. (25): 109- 128.

Company, Juan M. 1978. “El ghetto pornográfico”. La Mirada. Año 1 (1): 42- 45.

Lanzmann, Claude. 1994a. "Holocauste, la représentation impossible". Le Monde, Art \& Spectacles. 03/03: I, VII.

1994b. "Why Spielberg Has Distorted the Truth". Guardian Weekly. 03/04: 14.

\section{Fuentes orales}

Conversaciones con el Dr. Josep Maria Català, despacho universitario, Universitat Autònoma de Barcelona, Bellaterra, Barcelona.

Conversaciones con el Dr. Román Gubern, despacho privado, c/Hurtado, 32, Barcelona.

\section{Filmografía}

Hitchcock, Alfred. 1954. La ventana indiscreta (Rear Window). Estados Unidos: Paramount, color, $114 \mathrm{~min}$.

Lanzmann, Claude. 1985. Shoah (Shoah). Francia: Les films Aleph, color, 570 min.

Leconte, Patrice. 1989. Monsieur Hire (Monsieur Hire). Francia: Cinea / Hachette Première / Compaigne Europe 1 Communication / F.R.3 Films Productions, color, 81 min.

Losey, Joseph. 1951. El merodeador (The Prowler). Estados Unidos: Horizon / Eagle, blancoy negro, $92 \mathrm{~min}$. 
Spielberg, Steven. 1993. La lista de Schlinder (Schlinder's List). Estados Unidos: Dreamworks/ Amblin Entertainment, blanco y negro, $197 \mathrm{~min}$.

Tavernier, Bertrand. 1979. La muerte en directo (Death Watch). Francia - Alemania: Selta / Little Bear, color, 113 min.

Wenders, Wim. 1991. Hasta el fin del mundo (Bis ans Ende der Welt). Alemania - Francia Australia: Road Movies / Filmproduktion / Argos Films, color, 179 min.

\section{Videografía}

•Rec. 1993. “El placer de mirar”. España: Producciones Alta, Tele5. 19/09. 